\title{
Invited Paper - Fostering a Culture of Professional Faculty Development and Recognition of Engineering \& Engineering Technology Educators
}

\section{Prof. Dirk Schaefer P.E., Georgia Institute of Technology}

Prof. Dirk Schaefer serves on the faculty of the George W. Woodruff School of Mechanical Engineering at the Georgia Institute of Technology. Prior to joining Georgia Tech, Schaefer was a Lecturer in the School of Engineering at Durham University, UK. During his time at Durham, he earned a Postgraduate Certificate in "Teaching and Learning in Higher Education". He joined Durham from a Senior Research Associate position at Stuttgart University, Germany, where he earned his Ph.D. in Computer Science. Over the past 15 years, Schaefer has conducted research on product modeling, variant design, product lifecycle management, design-with-manufacture integration, standardized product data exchange, as well as digital and virtual engineering. His current research focus concerns the highly topical area of Cloudbased Design and Manufacturing (CBDM). A passionate educator, Dr. Schaefer also conducts research on Design Education, Personalized Learning, Distance Learning, and Professional Faculty Development. He has published more than 120 technical papers on Computer-Aided Engineering \& Design as well as Engineering Education, and has presented his work at numerous national and international conferences, symposia, and workshops around the world. Dr. Schaefer serves as editorial advisory board member and reviewer for several international journals in his field. In addition, he is a registered Professional Engineer in Europe (Eur Ing), a Chartered Engineering (CEng), a Chartered IT Professional (CITP), and a Fellow of the Higher Education Academy (FHEA) in the UK, as well as registered International Engineering Educator (Ing-Paed IGIP). 


\section{Fostering a Culture of Professional Faculty Development and Recognition of Engineering \& Engineering Technology Educators}

\section{Motivation and Background}

Few would disagree with the idea that educating the next generation of leaders in both academia and industry is at the heart of what engineering education is all about. This requires identifying the technological needs for the future, developing curricula with corresponding content, and delivering this content to learners in a variety of formats. While many faculty are dedicated to becoming outstanding educators, the general assumption is that holding a $\mathrm{PhD}$ in a core technical area is sufficient to be qualified as an academic educator. This no longer holds true (and maybe never did). The educator of today and near tomorrow needs to be able to teach in a number of different educational settings, including on-campus class rooms, asynchronous distance learning per video, virtual online learning environments for individual learners, or even massive open online courses (MOOCs) with perhaps more than a hundred thousand enrolled students on the Internet. As more and more IT-enabled learning environments and educational online tools emerge, new forms of instructional techniques, related pedagogical approaches to foster student learning in such settings, as well as associated examination and assessment methods are to be developed. In addition, the educator of today and near tomorrow is expected to know how to best address the learning needs of students from all walks of life, generations, countries and continents, and cultural backgrounds.

While Engineering and Engineering Technology (EET) departments have long adapted to the changing societal needs and revised their curricula so that their graduates will possess relevant skills and knowledge vital to industry and other potential employers, another key question needs to be addressed: "Who is going to educate and prepare the next generation of engineering educators?"1 Although it may seem obvious that becoming a professional educator and obtaining the relevant competencies and skills requires at least some amount of formal qualification, training and experience, current practice still does not sufficiently address the preceding question. In parallel with the changing EET curriculum, there has been a long-standing call to strengthen EET educators' capabilities and preparation to perform the task of educating students. This latter call, however, had remained virtually unanswered for more than a century. ${ }^{2}$

Over the past couple years, professional faculty development and recognition has been identified to be a critical dimension among the many complexities of transforming engineering education as a whole. For example, recent discussion within the engineering education community has included how to document progressive skills in scholarly teaching ${ }^{3}$, how to evaluate faculty instructional scholarship ${ }^{4}$, and whether a philosophy of engineering education can improve the practice of engineering education ${ }^{5-7}$. As these types of discussion move forward, it will be helpful to provide some context as to how these ideas might formally manifest themselves. This need is echoed in the report Creating a Culture for Scholarly and Systematic Innovation in Engineering Education, which involved many key players in engineering education ${ }^{8}$. In the following section, an overview of existing models for faculty development and recognition in teaching in higher education from around the world is provided. 


\section{Professional Faculty Development and Recognition around the World}

Around the world, several programs to support professional qualification, development and/or recognition for those teaching in Higher Education are known. They vary considerably in scope, administration and reputation 9 . An analysis of existing models reveals the following programmatic elements to guide comparison:

- Who is the governing association or body for the professional development program? These may be state entities, national or international societies, associations or academies, institutions, etc.

- Who is responsible for professional development program enforcement? - Enforcement may occur through accrediting agencies, state agencies, institutions, associations or academies, etc.

- How is the professional development program implemented at the national level? - The program may be nationwide, international, or locally controlled.

- How is the professional development program implemented at the local level? - Internal or external personnel may coordinate, deliver, and document professional development activities. Mentors may or may not be used or required.

- How is the professional development program included in accreditation? - Accreditation may require teaching certification for all or some faculty, documentation of professional development activities, or other teaching related items.

- Is participation compulsory or voluntarily? - Participation requirements vary widely.

- Who is/are the target group(s)? - While some countries focus on professional development for junior faculty, others address all those teaching in technical, engineering-related domains.

- What is the professional development program duration? - There may be multiple sequential levels of professional development activities and/or achievement, and programs vary from short courses to continuous development.

- What is the professional development program content? - Cultural expectations regarding teaching and learning can heavily influence the content of the professional development activities.

- How are qualifications recognized and/or rewarded? - Relationships between tenure/promotion and professional development vary from non-existent to tightly coupled.

Clearly criteria, standards, and policy regarding professional qualification for teaching in higher education are unique to each nation's needs, interests, and cultural expectations. Initial training of university teachers has been established in every university in the United Kingdom, Norway and Sri Lanka and is becoming increasingly common in many other countries. From beginning as small in scale, low in credibility and poorly supported, substantial training of 120-500 hours duration is now well embedded in many institutions across multiple nations, is often compulsory and is sometimes linked to probation or tenure. Major programs include a coherent series of meetings and various learning activities spread over a period of 4-18 months, usually with elements of both formative and summative assessment. Many of these programs are so-called postgraduate certificate courses subject to formal academic approval and quality assurance, which in addition lead to nationwide professional registration. ${ }^{9}$ 
Significant progress with regard to professional qualification, development, and recognition of engineering educators has been made in the UK. At some institutions, every new tenure-track hire has to participate in and successfully complete a compulsory 30 credit hour accredited training program in Teaching and Learning in Higher Education to pass probation and earn tenure. Successful completion also leads to certification and professional registration, and hence nationwide recognition based on common standards.

While the UK system mainly targets those teaching at university level, within the European Union the focus is on all those involved with teaching technical, engineering-related subjects. The International Society of Engineering Education (IGIP) at their headquarters in Austria has created a training program open to all "teaching teachers". Participation is voluntarily and often used as a means of continuous professional development to support career development. Successful completion of their program leads to professional registration as ING-PAED IGIP (International Professional Engineering Educator). IGIP, together with SEFI, the European Society of Engineering Education represent the largest network of higher education engineering institutions and of individuals involved in engineering education in Europe. It promotes information exchange about current developments in the field of engineering education between teachers, researchers and students in the various European countries.

While both the British and the IGIP programs are accredited, other countries have just embarked on the avenue of professional educational training. In Australia, for example, a number of efforts have been initiated at the federal level to ostensibly track and improve teaching quality. However, some claim these efforts are based on criteria that do not have the strength to make real changes in the quality of teaching occurring in engineering. Nonetheless, there are individual institutions whose engineering programs have made first moves towards more formal requirements regarding teaching quality. As yet, little is known about corresponding developments in Asia. Sources from Japan report on the development of a ranking scheme that links salary of faculty to practical experience of an educator in their chosen field.

Based on both statistical evidence as well as a substantial amount of informal and anecdotal evidence, the success of professional development programs in the educational sector has encouraged more and more countries across the world to begin to implement various types of programs. There is also a growing demand for professional certification and registration in the educational sector. Long-term, this might have a significant impact on faculty recruitment, promotion and tenure, salary development, and from an institutional perspective accreditation and fund raising. While these statements appear to hold true in general, there does not appear to be any single "best option" to be implemented within the US in the short term considering the current cultural and societal context.

\section{Opportunities and Challenges}

Utschig and Schaefer have outlined important opportunities and challenges relating to formal education-related faculty development on a large scale ${ }^{10}$. Questions explored are: What major opportunities exist regarding moving towards educational professional qualification for US Higher Education institutions, their faculty and students, industry, and society as a whole? How 
can resources be synergistically integrated to support such an effort? What are the major challenges or barriers present that must be overcome in order to create such a system?

In response to these questions, they present a concept map to explore how faculty educational development could support and greatly enhance an entire system revolving around faculty development in teaching and learning. Utilizing and reflecting upon the literature, major issues considered that relate to the questions above include various roles in the higher education engineering community; relationships between educational research, student learning outcomes, and engineering faculty; resources supporting engineering education, and the implication of different faculty reward structures. Analysis indicates that pieces already in place offer great potential to create the Engineering Education of 2020 for "The Engineer of 2020" if key barriers are addressed. An at-a-glance overview of the challenges and opportunities identified and thoroughly discussed in their paper ${ }^{10}$ is presented below:

Table $1^{10}$

Opportunities and challenges regarding implementation of formal education-related faculty development on a large scale

\begin{tabular}{|c|c|c|}
\hline & Opportunities & Challenges \\
\hline Roles & $\begin{array}{l}\text { - To provide clarity of purpose for all in educating our students (society). } \\
\text { - To make the various roles of professional educators transparent to key } \\
\text { stakeholders of the university system (students, parents, industrial } \\
\text { partners). } \\
\text { - Have a multi-level structure of professional educators who teach in } \\
\text { engineering disciplines (higher education, vocational training, short } \\
\text { courses for continuous professional development, etc.). } \\
\text { - For high-level associations (NAE, ASEE, ABET, NSF, etc.) to help define } \\
\text { minimum content of professional development programs and accredit } \\
\text { such programs. } \\
\text { - Capitalize on admin heavy participation in leadership of national } \\
\text { organizations like NAE, ASEE... to effect change. } \\
\text { - Departments - chairs have opportunity to guide outcomes. } \\
\text { - For institutions/department to certify individuals completing professional } \\
\text { training programs. }\end{array}$ & $\begin{array}{l}\text { day, there is no formal qualification needed to } \\
\text { Higher Education. } \\
\text { core technical area does not necessarily mean } \\
\text { or is qualified to be an effective educator. } \\
\text { no professional recognition for educators. } \\
\text { ions - retain independence in light of pressures } \\
\text { tional organization such as NAE, ASEE, NSF, } \\
\text { change for all in the face of traditional faculty } \\
\text { my ... } \\
\text { nal requirements and classifications based on } \\
\text { trated teaching knowledge/skills/ability. } \\
\text { lects between different needs for different }\end{array}$ \\
\hline
\end{tabular}




\begin{tabular}{|c|c|c|c|}
\hline Resources & $\begin{array}{l}\text { - Interdisciplinary research synergy leading to } \\
\text { additional grant opportunities. } \\
\text { - Current engineering education community can } \\
\text { take on the responsibility to lead this field of } \\
\text { professional development. } \\
\text { - Established teaching and learning centers } \\
\text { with engineering expertise may use their } \\
\text { resources (faculty, staff, and facilities) to offer } \\
\text { programs to other departments and external } \\
\text { academic units or participants. }\end{array}$ & \multicolumn{2}{|c|}{$\begin{array}{l}\text { - Administration of professional development programs across all levels (national, } \\
\text { state-wide, institutional, departmental). } \\
\text { - Significant seed funding is needed to develop, administer and establish programs, } \\
\text { publish materials, advertise etc. } \\
\text { - Increasing funds (internal and external) for teaching facilities and equipment. } \\
\text { - Providing time for faculty to take part in such programs. } \\
\text { - Enhancing data demonstrating impact of faculty development in this area: ex; } \\
\text { Flagship pilot programs targeting various levels of certification are needed to } \\
\text { demonstrate usefulness and impact. }\end{array}$} \\
\hline $\begin{array}{l}\text { Relation- } \\
\text { ships }\end{array}$ & \multicolumn{2}{|c|}{$\begin{array}{l}\text { - Cross-disciplinary research between faculty from engineering and education leading } \\
\text { to joint scholarly publications and research grants. } \\
\text { - Funding agencies can further emphasize relevance of educational components to } \\
\text { their programs. } \\
\text { - Closer collaboration between high-level associations to jointly shape the future of } \\
\text { Engineering Education at a national level. } \\
\text { - Elevate public image and occupational status of engineering educators. } \\
\text { - Raise students' and parents' confidence in education offered at higher education } \\
\text { institutions. } \\
\text { - High-level associations can work together toward a common goal. } \\
\text { - More frequent and active participation in international Engineering Education } \\
\text { community to compare US standards to European and Asian standards in order to } \\
\text { become leaders on a global scale. }\end{array}$} & $\begin{array}{l}\text { - Institutions and departments do not have } \\
\text { sufficient personal able to foster such } \\
\text { developments. } \\
\text { - Overcome fear of making teaching and } \\
\text { learning a public exercise rather than } \\
\text { autonomous activity. } \\
\text { - Convey to public all the roles of an } \\
\text { educator. They need to understand that it } \\
\text { means much more than the traditional } \\
\text { teaching at school as practiced decades } \\
\text { ago. } \\
\text { - Agree on how to evaluate performance on } \\
\text { common scales and utilizing all } \\
\text { stakeholders. }\end{array}$ \\
\hline
\end{tabular}

Fortunately, current conditions in the US, as outlined in Table 1, display more opportunities than challenges. This indicates great potential for moving forward. Fostering and growing relationships among the various constituents in the engineering education community, along with delivering rewards that match the language in mission statements and professional expectations for promotion and tenure, are certainly possible under current conditions. However, the challenges still represent significant barriers. Resources, both in funding and human capital, may always be insufficient unless a clear shift in roles occurs such that professional development and faculty performance in engineering education philosophically become clear competitors with research. Currently, there is no infrastructure in place to support a philosophical shift in how faculty, departmental, and institutional roles can leverage widespread implementation of faculty development as educators in engineering. Nonetheless, overcoming these barriers is essential. Without doing so it will be virtually impossible to offer an Engineering Education of 2020 that achieves the learning outcomes desired for The Engineer of 2020.

\section{Critical Program Elements for Success}

Considering the context summarized above, a framework for a national faculty development and recognition program may be constructed around three critical program elements that are deemed essential in developing any formal teaching and learning faculty development system intended to produce widespread measurable impact ${ }^{11}$.

Critical element \#1: Programs will evolve and be supported by a nationally respected society or academy.

A sponsoring society or academy needs to fulfill a number of requirements.

- Prominent and respected national reputation.

- Member influence across many types of institutions concerning engineering education. 
- Stakeholder in the success of the program.

- Able to commit resources to the program.

○ Time and space at national conferences and other events.

- Web presence.

- Participation tracking.

- Highly visible and respected personality as a champion.

- Viewed as independent of institutions it serves.

- Linked to accrediting agencies and other oversight groups.

- Significant member involvement in EET education research.

Critical element \#2: Programs will be supported by qualifying criteria or standards at several levels of expertise with clear criteria at each level.

Different levels of certification represent the continuous evolutionary journey one undergoes as an educator. The following three levels are proposed: Tier 1: Theory - foundations of teaching and learning. Tier 2: Scholarship - educational research and scholarly work in the field. Tier 3: Practice and Portfolio - reflective teaching portfolio development and peer mentoring.

Tier 1 Content: Foundations of Teaching and Learning - Putting theory into practice

Areas of focus for this level of faculty development should include:

- Learning styles/Learning processes.

- Learning theory.

- Course and curriculum design.

- Constructive Alignment.

- Active learning (student engagement).

- Assessment and Evaluation.

- Teaching with Technology.

Tier 2 Content: Scholarship:

In this level participants become engaged in a largely self-directed process of developing, documenting, and exploring their own 'mental model' of teaching and learning. The goal of Tier 2 is to develop participants' ability to:

- Create effective instruments to collect evidence of student learning.

- Interpret and evaluate the evidence in theoretical terms, appealing to the research literature on conceptions of learning, approaches to learning, and the (qualitative and quantitative) modeling of learning outcomes.

- Consider implications of the evidence in terms of developing a basis for reflective practice .

Tier 3 Content: Practice:

The final stage of the learning process for program participants is to become reflective practitioners who pursue opportunities to help others understand what is happening in their 
respective teaching and learning environments. Individuals will participate in peer mentoring and peer coaching activities in order to accelerate their personal growth and to provide quality feedback to others using a variety of tools.

Critical element \#3: Programs will accommodate flexibility in implementation across a variety of university administrative structures and cultures.

Each college and university deserves the authority to implement faculty development in ways that make sense within its own institutional culture and administrative structure. Because each institution can approach their system independently, the intent should not be to prescribe the methods, but rather the standards to which they must rise as measured through the outcomes they achieve. These outcomes can then be held up to statewide or national standards reflected in critical element \#2 and enforced via the sponsoring society as discussed in critical element \#1. The system would thus reflect accreditation processes in that each institution writes their own outcomes and designs systems to achieve those outcomes in light of the accountability being tackled through an external entity. Keeping these guidelines in mind it is recommended that individual institutions should control (1) specific curricula (2) content emphases or specialties (3) timelines (4) participants, instructors, and mentors and (5) inclusion/weighting in the tenure process. However, they should not control (1) certification levels and (2) certification standards.

\section{A Framework for a National Initiative and a Proposed Level 1 Curriculum}

The American Society for Engineering Education has recently proposed a national level faculty

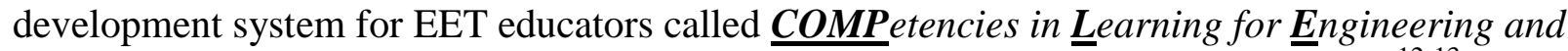
$\underline{\boldsymbol{E}}$ ngineering $\underline{\boldsymbol{T}}$ echnology $\underline{\boldsymbol{E}}$ ducators (COMPLEETE), formerly called SPEED (2010) ${ }^{12-13}$. As the foundational development of a sustainable long-term system, they describe four goals in their proposal:

- Define a framework of core teaching competencies and associated metrics.

- Design an adaptable curricular framework for imparting the core competencies.

- Establish administrative processes for recognizing faculty attainment of specific teaching competencies and certifying instructional development providers in implementing aspects of the curricular framework for imparting core teaching competencies.

- Engage multiple constituencies throughout the design, development and early implementation phases for the above goals and the overall program.

In a nutshell, COMPLEETE is an initiative for a national program to build and recognize educator excellence in engineering and engineering technology. This recognition occurs as the educator progresses through three levels of achievement. These are a foundational level representing critical areas of competence which contribute to building quality teaching and learning environments in any setting, a scholarly practitioner level where participants further strengthen their skills and begin to systematically investigate learning in their classrooms, and a reflective mentor level where participants contribute and give back to the engineering and engineering technology community of practice ${ }^{12}$.

In a recent paper, Utschig et al. propose a teaching and learning curriculum for COMPLEETE based on current national trends ${ }^{14}$. The proposed curriculum is based on a comparison of nine 
existing faculty development programs including STEMES ${ }^{15}, \mathrm{EXCEED}^{16}$, Pacific Crest $^{17}$, NETI $^{18}$, U-Michigan ${ }^{19}$, Northern Illinois ${ }^{20}$, and CIRTL's Delta program ${ }^{21}$ within the US, plus international models from the $\mathrm{UK}^{1}$ and $\mathrm{IGIP}^{22}$. These programs have informed the structure and content of the proposed curriculum, which is specifically targeted to benefit engineering and engineering technology instructors in higher education. In the current proposal, only level 1 of the COMPLEETE framework is addressed because the initial efforts of the COMPLEETE program will focus on this level, and further because the proposed curriculum will likely be adapted based on community input, implementation, and review, thus defining more detailed needs for levels 2 and 3 over time.

Level 1 - Foundations:

A. Proposed Level 1 Aims:

- To provide an overview of teaching and learning practice and theory in Engineering and Engineering Technology Education, addressing the core knowledge and professional values educators are expected to have to be able to teach effectively and efficiently at their respective institutions.

- To begin to establish in participants a culture of reflective practice and evaluation of their own teaching practice, and of the learning of their students; and to build a broader community of practice among practitioners.

\section{B. Proposed Level 1 Learning Outcomes:}

Upon successful completion of Level 1 participants will:

- Have evaluated aspects of their current teaching practice within the context of learning and teaching literature (reflecting knowledge and critical understanding of the following teaching and learning activities: teaching and the support of learning; contribution to the design and planning of learning activities; assessment and giving feedback to learners; developing effective learning environments and learner support systems).

- Have gained an understanding of the learning process, drawing on recognized learning theories.

- Have developed an understanding of students, including issues of intellectual and social development, learning styles and differences in student approaches to learning.

- Have been engaged in instructional design at lecture, module, course, or curriculum level.

- Have been exposed to various methods of instructional delivery, including an overview of teaching methods appropriate for different instructional goals and environments, including both large and small classes.

- Have designed and used appropriate methods to assess student learning and give feedback to learners.

- Have developed an understanding of how to make effective use of educational technology.

- Have engaged in reflective practice and continuous learning.

The proposed curriculum which accompanies these goals and intended outcomes is built from the overarching criteria proposed in the COMPLEETE project as presented in various publications over the past couple years ${ }^{2,12-13,22-24}$. The curriculum revolves around seven areas of core competency which were first articulated as a synthesis of faculty development needs by an experienced faculty development expert in engineering on the original SPEED team and then 
revised based on discussion among others on the SPEED and, later, COMPLEETE project team. The seven areas or core competence are shown in Table 2.

\begin{tabular}{|c|l|}
\multicolumn{2}{|c|}{ Table 2: Core Competency Areas } \\
\hline Area & Title \\
\hline 1 & learning theory \\
\hline 2 & student development \\
\hline 3 & instructional design \\
\hline 4 & instructional facilitation methods \\
\hline 5 & assessing and providing feedback \\
\hline 6 & instructional technology \\
\hline 7 & reflective practice \\
\hline
\end{tabular}

It is also consistent with previously proposed critical elements for successful faculty development programs at a national level in the $\mathrm{US}^{11}$ and serves as one response to numerous calls for a national reform. Finally, it integrates with values and programming already present within $\mathrm{ASEE}^{25}$, serves as a foundation for further development at higher levels, and is flexible to suit the needs of a diverse instructional community.

\section{DRAFT MODULE STRUCTURE for LEVEL 1}

The first five modules are proposed as required core modules for all COMPLEETE participants. These modules are well represented in existing curricula and thus form a broad and generally agreed upon foundation of teaching and learning competencies desired for engineering and engineering technology educators.

\section{A. Core Module 1-Learning Theory:}

Outcome: Understanding the learning process, drawing on recognized learning theories.

Narrative: A practical overview of theories of learning and teaching in Higher Education, with a focus on the disciplines of engineering and engineering technology. This includes an overview of current cognitive and constructivist learning theories with a focus on their application to undergraduate instruction.

- Understanding student learning.

- Constructivism.

- Approaches to learning: deep learning, surface learning, strategic learning.

- The Kolb learning cycle.

- SOLO taxonomy of levels of understanding.

- Bloom's taxonomy of learning.

- Learning styles.

- Problem-based Learning.

- Project-based Learning.

\section{B. Core Module 2 - Student Development:}

Outcome: Understanding students, including issues of intellectual and social development, learning styles and differences in student approaches to learning. 
Narrative: An introduction to understanding elements of student development which impact teaching and learning such as students intellectual and social development, learning style preferences and approaches to learning.

- Encouraging student motivation.

- Teaching and learning in small groups.

- Teaching and learning in large groups.

- Student supervision: one on one, e.g. projects, theses, dissertations, etc.

- Reflective practice.

- Ethics.

\section{Core Module 3 - Instructional Design:}

Outcome: Introduction to instructional design, including both course and curriculum design.

Narrative: An introduction to the theory of constructive alignment (of intended learning outcomes, learning and teaching methods and assessment) to be used in course and curriculum design.

- Organizing teaching and learning.

- Outcome-based planning.

- Module and course design.

- Constructive alignment (Biggs).

D. Core Module 4 - Instructional Facilitation Methods:

Outcome: Instructional delivery, including an overview of teaching methods appropriate for different instructional goals and environments, including both large and small classes.

Narrative: An overview of instructional techniques that might be employed in large group or small group teaching situations, with an emphasis on approaches that might shift the environment of the classroom from teacher-centered instruction toward student-centered learning.

- Structuring lectures.

- Increasing student-teacher interaction.

- Managing the Classroom Learning.

E. Core Module 5-Assessing and providing feedback to learners:

Outcome: Designing and using appropriate methods to assess student learning.

Narrative: Purpose of assessment, principles of assessment, formative and summative assessment, methods of assessment, assessing groups, peer and self-assessment, devising assessment criteria, providing feedback.

- Assessment and evaluation.

- Formative and summative assessment.

- Methods of giving feedback. 
- Assessment methods/tools.

- Developing rubrics.

The next two modules are proposed as electives. A COMPLEETE participant would choose at least one of these two modules to attain level 1 in the COMPLEETE curriculum. Some, but not all, existing curricula address these modules in a significant way.

\section{A. Elective Module A-Instructional Technology:}

Outcome: Making effective use of technology.

Narrative: An introduction to available tools and the effective use of technology to promote learning, including principles of e-learning.

- E-learning.

- Virtual Learning Environments.

\section{B. Elective Module B-Reflecting on learning and teaching:}

Outcome: Engaging in reflective practice and continuous learning

Narrative: An introduction to the role of reflection in professional practice.

- Reflective practice (currently this topic remains distinct to this module, but upon further discussion will likely be distributed throughout the curriculum, with a focus reach in this elective module).

- Developing portfolios.

- Classroom peer observations.

To see the above national framework or curriculum put into practice, a transformation of engineering education crossing traditional collaborative boundaries will be required.

\section{Closing thoughts}

From an international perspective, there are a number of exciting opportunities to further foster a global culture of professional EET faculty development and recognition. Educators who have earned professional registration and recognition based on a national standard in their home countries should be provided an opportunity to have their registration transferred or extended to obtain an equivalent status in another country in which they practice. This may require national engineering education associations to partner and create mutually agreeable mappings of national standards, or perhaps an overarching international standard. Such an endeavor might be approached in a way similar to how professional engineering registration is handled in Europa. Professional Engineers registered in one country, for example Chartered Engineers (CEng) from the UK, may become registered professional European Engineers (Eur Ing) if they meet a set of overarching requirements that are accepted by all partnering national engineering association. In light of the preceding, we might also think about extending the current ASEE COMPLEETE model to international level to develop an overarching program in collaboration with our international peer organizations. Through a global, international provider network of content 
modules and the use of modern technology, for example MOOCs, it could become possible to create a highly customizable system that leads to professional registration and recognition as, for lack of a better term, Global Engineering Educator and at the same time allows to personalize or tailor the program content for an individual in a way that best corresponds to his or her national requirements.

\section{Acknowledgements}

The material presented in this paper was compiled mainly from a number of articles previously published by the members of the SPEED/COMPLEETE Working Group, namely Dirk Schaefer and Tristan T. Utschig (Georgia Institute of Technology), Donald P. Visco, Jr. (University of Akron), J.P. Mohsen (University of Louisville), Norman L. Fortenberry (ASEE), Michael Prince (Bucknell University), and Cynthia Finelli (University of Michigan).

\section{Bibliography}

1. Schaefer, D. (2007): “Advising the Advisor: Professional Development of Junior Faculty.” In: Thomas, B. (Ed.), ASEE Southeastern Section Annual Conference: "Advancing Scholarship in Engineering Education: Lessons Learned From a Year of Dialogue," Louisville, Kentucky, USA, April 1-3, 2007, pp. 2.12.

2. Melsa, J.M., Mohsen, J.P., Schaefer, D. and D. Visco Jr. (2009): "Strengthening the Performance of Engineering and Technology Educators across the Disciplines (SPEED)" 2009 ASEE Annual Conference \& Exposition, Austin, Texas, June 14-17, 2009.

3. Fortenberry, N. (2005): Panel Discussion: Engineering Education and R\&D: Building Capacity and Building Community. $35^{\text {th }}$ Annual Frontiers in Education Conference, Indianapolis.

4. National Academy of Engineering (2009): Developing Metrics for Assessing Engineering Instruction: What Gets Measured is What Gets Improved. Washington, D.C.: National Academies Press.

5. Smith, K. (2003): Educational Philosophy. Journal of Engineering Education, 92(3), 203-205.

6. Heywood, J. (2007): Special Session: Can Philosophy of Engineering Education Improve the Practice of Engineering Education? $37^{\text {th }}$ Annual Frontiers in Education Conference. Milwaukee.

7. Heywood, J., Carberry, A., and Grimson, W. (2011): A Select and Annotated Bibliography of Philosphy in Engineering Education. Frontiers in Education Conference (FIE) 2011 (pp. PEEE-1-PEEE-26). Rapid City: IEEE Conference Publications.

8. ASEE (2009): Creating a Culture for Scholarly and Systematic Innovation in Engineering Education - Phase 1 Report. Washington, D.C.: ASEE.

9. Schaefer, D. and T.T. Utschig (2008): "A Review of Professional Qualifications, Development, and Recognition of Faculty Teaching in Higher Education around the World," 2008 ASEE Annual Conference \& Exposition, Pittsburgh, Pennsylvania, June 22-25, 2008.

10. Utschig, T.T. and D. Schaefer (2008): "Opportunities and Challenges in Professional Education-related Faculty Development in the US." 2008 IEEE - Frontiers in Education Conference, Saratoga Springs, New York, October 22-25, 2008.

11. Utschig, T.T. and D. Schaefer (2008): "Critical Elements for Future Programs Seeking to Establish Excellence in Engineering Education through Professional Qualification of Faculty Teaching in Higher Education." IACEE 11th World Conference on Continuing Engineering Education, Atlanta, Georgia, May 20-23, 2008.

12. Visco, D., Schaefer, D., Utschig, T.T., Mohsen, J.P., Fortenberry, N.L., M. Prince, and C. Finelli (2010): "Preparing for Participation in SPEED: An ASEE Initiative for a Nationally Recognized Development Program for Engineering Educators." 2010 ASEE Annual Conference and Exposition, Louisville, Kentucky, June 20-23, 2010, paper \# AC2010-1940. 
13. Schaefer, D., Visco, D., Utschig, T.T., Mohsen, J.P., Fortenberry, N.L., M. Prince, and C. Finelli (2010): “SPEED An ASEE Initiative for a Nationally Recognized Development Program for Engineering Educators." 2010 ASEESE Annual Conference, Blacksburg, Virginia, April 18-20, 2010.

14. Utschig, T., Schaefer, D., and D. Visco (2012): “A Proposed Teaching and Learning Curriculum for SPEED Based on Current National Trends" 2012 IEEE - Frontiers in Education Conference, Seattle, Washington, October 3-6, 2012, paper \# 1569562127.

15. Center for the Integration of Research Teaching and Learning, "The 12th Annual Science, Technology, Engineering, and Mathematics (STEM) Education Scholars Program," 2007. [Online]. Available: http://www.cirtl.net/STEMES/. [Accessed 2012].

16. American Society of Civil Engineers, "ExCEEd: Excellence in Civil Engineering Education," 2012. [Online]. Available: http://www.asce.org/exceed/. [Accessed 2012].

17. M. Rhiner, L. Abernathy, J. Weglarz, R. Jaffe, M. Thomas and C. Stephenson, "Master Teacher Program," 2011. [Online]. Pacific Crest. Available:

http://www.facultyguidebook.com/kirkwood/docs/Master_Teacher_Program_Design_041211.doc. [Accessed 2012].

18. The National Effective Teaching Institute, "The National Effective Teaching Institute," [Online]. Available: http://www4.ncsu.edu/unity/lockers/users/f/felder/public/NETI.html. [Accessed 2012].

19. University of Michigan College of Engineering, "Certificate in Engineering Education Research," [Online]. Available: http://www.engin.umich.edu/teaching/crltengin/rackhamcert.html. [Accessed 2012].

20. Northern Illinois University College of Engineering, "The Scholarship of Teaching and Learning: The CEET Faculty Development Program on Teaching and Learning," 2009. [Online]. Available: http://www.niu.edu/CEET/p20/scholarship/workshops/2009workshops.pdf. [Accessed 2012].

21. University of Wisconsin-Madison Center for the Integration of Research, Teaching and Learning, "Delta Program," 2012. [Online]. Available: http://www.delta.wisc.edu/index.html. [Accessed 2012].

22. E. Lickl, "Engineering Education Societies in Europe and the Needs of Industry," in ASEE Distinguished Lecture Series, Louisville, KY, 2010.

23. J.P. Mohsen, "GUEST EDITORIAL - SPEED: A Concept for Enhancing the Quality of Engineering Education," Journal of STEM Education, Vol.10, No. 1, 2009, pg. 5-6.

24. J.P. Mohsen, "PRESIDENT'S LETTER - Professional Development Is Key" PRISM, ASEE, Sept. 2009.

25. American Society for Engineering Education, "American Society for Engineering Education: About--> The organization --> Our Mission." [Online]. Available: http://www.asee.org/about-us//the-organization/ourmission. [Accessed 2012]. 